\title{
Communication, Commitment \& Trust: Exploring the Triad
}

\author{
Rachid Zeffane, $\mathrm{PhD}$ \\ Department of Management, Marketing \& Public Administration \\ College of Business Administration, University Of Sharjah \\ United Arab Emirates \\ Tel: 971-6-505-3557Ｅ-mail: zeffaner@sharjah.ac.ae \\ Syed A Tipu \\ Department of Management, Marketing \& Public Administration \\ College of Business Administration, University of Sharjah \\ United Arab Emirates \\ E-mail: stipu@sharjah.ac.ae \\ James C Ryan \\ Department of Management, Marketing \& Public Administration \\ College of Business Administration, University of Sharjah \\ United Arab Emirates \\ E-mail: jryan@sharjah.ac.ae
}

Received: January 4, 2011 Accepted: February 9, 2011 doi:10.5539/ijbm.v6n6p77

\begin{abstract}
Despite growing interest on the issues of communication, trust and commitment, studies examining the interplay between all of these three variables are lacking. This paper attempts to address this gap. It draws on survey data involving 244 employees from a medium-size food processing organization operating in NSW (Australia). The study explored relationships between communication, trust and commitment. Trust was measured by a six-items composite scale assessing overall beliefs in good intentions of organization participants as well as the degree of faith/trust in various actors in the organization, including co-workers and managers at various levels of the hierarchy. Correlation analysis revealed that perceived effectiveness of communication between management and employees, commitment $\&$ pride in working for the company and trust were significantly interrelated. However, the relationship between Trust and Communication was the strongest, with commitment also showing a significant relation to Trust. On the other hand, the relationship between commitment and communication was relatively weaker. The results demonstrate the importance of effective communication within organizations as it relates to trust and organizational commitment. In particular, the study shows that trust and commitment do not just happen; they are forged and maintained through effective communication. Implications for management practice and future research are discussed.
\end{abstract}

Keywords: Trust, Communication effectiveness, Organizational commitment, Loyalty

This paper explores the relative impact of communication effectiveness, job satisfaction and participation on trust climate, including trust in managers. It draws on survey data involving 244 employees from a medium-size food processing organization operating in NSW (Australia). The study explored factors that are most likely to affect trust climate. Trust climate was measured by a six-items composite scale assessing overall beliefs in good intentions of organization participants as well as the degree of faith/trust in various actors in the organization, including co-workers and managers at various levels of the hierarchy. Regression analysis revealed that perceived effectiveness of communication between management and employees and commitment $\&$ pride in working for the company were overwhelmingly the most influential factors affecting the likelihood of trust 
climates and trust in Management. Further scrutiny of the data revealed that aspects of communication that most strongly affect trust climate are perceptions of effective communication with senior management. These results are supportive of previous studies and reinforce the underlying importance of communication effectiveness in general and communication with senior management in particular in nurturing trust and trust climates in organizations. Implications for theory, practice and future research are discussed.

Research examining the linkages between communication, trust and commitment is abundant. However, very few studies have examined the relationships between all three in a single study. Studies have tended to examine these in a dyadic fashion. In other words, previous research has tended to either focus on relationships between communication \& trust (Stevenson \& Gilly, 1991; Ruppel \& Harrington, 2000; De Ridder, 2006; Harry, 2006; Rosli \& Hussein, 2008) or trust \& commitment (Tyler \& Doerfel, 2006; Welch \& Jackson, 2007) or even communication and commitment (van den Hoff and de Ridder 2004; van vuuren et al 2007; Bambacas \& Patrickson, 2008). Very few studies have examined the relationships between all three variables in a single study. Of even greater concern, there is no consensus on the direction of these relationships (Anderson \& Narus, 1990).

For instance, several studies hypothesized and concluded that it is communication that affects trust formation (Allert \& Chatterjee, 1997; Massey \& Kyriazis, 2007; Kottila \& Ronni, 2008, Webster \& Wong, 2008; Thomas et al, 2009). In contrast, several other studies found that trust precedes effective communication and is a critical determinant of trust building (Mellinger. 1956; Robert \& O'Reilly, 1974; Dwyer et al 1987; Gaines, 1980; Chory \& Hubbell, 2008). In addition other researchers, such as Anderson and Narus (1990), have tended to view the relationship between communication and trust as interactive in that effective communication is a necessary antecedent to trust which in turn reinforces positive communication. In the same vain, while some studies examining the link between trust and commitment concluded that trust precedes commitment (see for example Hess \& Story, 2005; Tan \& Lim, 2009; Ozag, 2006) other studies implied or purported that it is commitment (or feelings of loyalty to the organization) that in fact enhances the likelihood of trust (Wong \& Sohal, 2002). Others simply imply that trust and commitment both impact other organizational outcomes and as such have different antecedents (see for example Tang \& Fuller, 1995; Iverson et al, 1996). Moreover studies examining the relationship between communication and commitment have tended to argue that communication precedes commitment and influences it. (van den Hoff \& de Ridder 2004; van vuuren et al 2007; Bambacus \& Patrickson, 2008). Other studies take a more cautious approach and simply state that communication and commitment are closely interrelated (Varona, 1996).

To address this research gap, this paper examines the interrelations between communication, trust, and commitment. It draws on survey data involving 244 employees from a medium-size food processing organization operating in NSW (Australia). What follows is a brief review of the relevant literature, a presentation of the methodology and an outline of the research findings. We then discuss the study results by reference to previous research and reflect on their relevance for future research and management practice.

\section{Communication and Trust}

An overwhelming body of research found and argued that communication, defined as "the formal as well as informal sharing of meaningful and timely information" is closely related to trust, and defined trust in an organizational context as "an expectancy held by an individual or group that the word, promise, verbal or written statement of another individual or group can be relied upon" (Rotter, 1967; Anderson \& Narus 1984). Here the argument is that communication is a major predictor of interpersonal trust, therefore underpinning a one-way relationship between the two variables. However, this view is not commonly shared. Several studies found and argued that trust can affect communication. So the relationship between communication and trust seems to be a complex one and it is difficult to assume a definite direction of the relationship between these two variables. This complexity has triggered an ongoing debate in the literature exploring different dimensions of the trust-communication dyad. Some studies, simply take the view that communication plays a moderating role in the relationship between trust and other organizational variables. For instance Allert and Chatterjee (1997) argued and showed that an array of factors such as leadership style and the overall corporate culture tend to shape the nature and effectiveness of corporate communication which in turn triggers the likelihood of a trusting culture. Moreover, their model also triggers confusion as it also depicts that a trusting culture in turn would influences the corporate communication process. This points to a cyclical pattern underpinning the relationship between communication and trust as two-way systematical process. To further highlight this point we present below the relevant literature on both sides of the "fence".

\subsection{Communication affects Trust?}

Much of the research purporting effects of communication on trust has considered relationships at both the 
individual and organizational levels. An overwhelming number of such studies have posited that communication is a precedent to trust. Allert and Chatterjee (1997) asserted that the communication culture promoted by leadership tends to facilitate nurturing trust based mutual relationships. Ruppel and Harrington (2000) explored the link between trust and communication and found significant positive correlation between communication and employee trust. Drawing upon the communication accommodation theory and social identity theory, Willemyns et al (2003) examined the patterns of trust and power in manager-employee relationships. This study revealed that the managers' communication themes such as dominance, coercive power, lack of willingness to listen, lack of support or empathy and face threat, could affect the perceptions of 'in-groupness' which ultimately erode the level of trust. In another study, Ball et al (2004) explored the role of communication and trust in explaining customer loyalty. Although, they came to the conclusion that both trust and communication affect customer loyalty, they also reported that communication is an antecedent of trust. All in all, trust and communication go hand in hand. Attention to the quality and frequency of communication goes a long way toward creating an atmosphere of trust. Therefore, effective communication is an essential ingredient for trust between employees as well as trust between managers and employees (de Ridder, 2006). Massey and Kyriazis (2007) investigated patterns of interpersonal trust between marketing managers and $R \& D$ managers during new product development projects. They also found that the communication quality instead of frequency had significant affect on interpersonal trust. Kottila and Ronni (2008) also found that the quality of information is more important than the frequency of information in creating trust.

Huang et al (2008) investigated the role of the communication channels in trust formation between boundary spanning individuals from different organizations. It was revealed that face-to-face communication has more comprehensive impact in terms of facilitating the interpersonal trust building mechanisms. Rosli and Hussein (2008) examined the characteristics that develop a communication climate and the communication dimensions that relate to these practices. They found that the communication dimensions- trust, subordinate interaction, openness in downward communication, listening in upward communication, and supportiveness contributed 52 percents to trust climate. Similarly, Ellonen et al (2008) argued that the institutional trust (e.g, trust in organization's strategy and human resource policies) could be enhanced with the help of transparent and understandable communication. This indicates that effective communication among employees and between employees and their managers could result in mutual trust based relationships, a view also shared by Ayoko and Pekerti (2008). More recently, Thomas et al (2009) explored the relationship between communication and trust by focusing on the quality and quantity of the information being communicated. It was found that quality of information is the best predictor of trust with regard to the communication among coworkers and supervisors. On the other hand, the quantity of information was a major predictor of trust while communicating with the top management.

\section{Trust affects Communication?}

Despite the bulk of research evidence pointing to communication as a precedent to trust, a number of studies have in fact found and purported the opposite. In a very early study of 330 professional scientists, Mellinger (1955) explored the affect of distrust on communication and found that if the sender does not trust the receipt, then he or she is likely to initiate evasive, compliant, or aggressive communication. Gaines (1980) explored the effect of trust on communication and found statistically significant affect of trust on the distortion of upward communication. A study conducted by van Vuuren et al (2007) also revealed that trust could influence employee's satisfaction with supervisor's communication. In a study of 144 working adults, Chory and Hubbell (2008) explored the relationships between managerial trust and employee antisocial organizational behavior and communication. Their study revealed that the subordinates are less likely to communicate negatively and exhibit antisocial organizational behavior if they trust their managers and believe that their performance appraisal is fair assessment.

\section{Trust and Commitment}

It is widely understood and agreed that organizational commitment and trust are deeply interrelated. In fact, some of the prevailing views are that both commitment and trust are fluid processes created through symbolic interaction with organizational actors where the interaction with these actors, over time, influences commitment to the organization (Tyler \& Doerfel, 2006). Like trust, the notion of organization commitment incorporates a number of behavioral and emotional facets such as going the extra mile, pro-active participation, and feelings of pride and loyalty in the organization (Meyer et al, 1990; Allen \& Meyer, 1996; Welch and Jackson, 2007; Jacobs, 2008). Again here, some researchers have expressed caution on pointing to a directive relationship while others were more forthcoming in that regard. Ozag (2006) expressed his caution when he examined findings of the relationships between trust and both normative and continuance commitment of merger survivors. He found a 
significant relationship between trust and normative commitment while the relationship between trust and continuance commitment was not significant.

On the other hand, several studies were more forthcoming than others. A trust-commitment model proposed by Hess and Story (2005) showed that trust significantly contributes to commitment. Other authors (for example, Wong \& Sohal, 2002; Kwon \& Suh, 2005; Kwon \& Sun, 2006) also found significant effect of trust on organizational commitment. As noted in the literature exploring the trust-commitment dyad, it has been established that trust precedes commitment. More recently, Tan and Lim (2009) posited that trusting relationships among employees is a predictor of the degree to which employees would trust an organization which can subsequently lead to organizational commitment.

\section{Communication and Commitment}

By comparison to studies examining relationships between trust \& commitment and trust and communication, relatively fewer studies have examined the direct linkages between communication and commitment (see for example Robert \& O'Reilly, 1974; van Vuuren et al, 2007; Bambacas \& Patrickson, 2008). However, there is a limited body of research which points to the effect of communication on organizational commitment. Guzley (1992) found that employees' perceptions of organizational communication were positively correlated with the employees' organizational commitment. Varona (1996) found significant positive relationship between communication and employees' organizational commitment. Thornhill et al (1996) also asserted that communication should be seen as a key element of organizational strategy for promoting employees' involvement which will instil the sense of organizational commitment. van den Hoff and de Ridder (2004) explored the influence of the communication climate on knowledge sharing. It was found that the constructive communication climate positively influence knowledge donating, knowledge collecting and affective commitment. Van Vuuren et al (2007) examined the impact of supervisor's communication on employee's organizational commitment and found a significant effect of communication satisfaction on commitment. In a more recent study of senior human resource managers, Bambacas and Patrickson (2008) examined how interpersonal communication skills affect organizational commitment. It was found that the managers' ability to listen, clarity and of the message, and ability to lead were of highest importance to the managers when they intended to enhance subordinates' organizational commitment.

\section{Triad of Communication, Trust, and Commitment}

Very few previous studies have made a deliberate attempt to examine the triad of relationships between communication, trust and commitment. We could only find two important studies which have incorporate these three variables with inconclusive results. In their seminal study, Robert and O'Reilly (1974) examined the affect of trust on organizational commitment and found that the trust in superior affected respondents commitment to the organization. At the same time, their study revealed statistically significant inter-correlation between trust in superior and the satisfaction with the communication. However, the relationship between satisfaction with communication and organizational commitment was not statistically significant. In a study of 144 employees, Gopinath and Becker (2000) examined the relationships among managerial communication, procedural justice of layoffs and employees' attitudes under the conditions of divestiture. The study concluded that the managerial communications which helped the employees in understanding the divestiture predicted higher level of organizational commitment. At the same time, they reported that that communication was not the predictor of employee's trust. Also, in a study of five organizations (with 791 respondents distributed across 19 work units) de Ridder (2006) attempted to answer the question of whether organizational communication helps foster a positive attitude towards the strategic direction of an organization. They concluded that there are two ways to foster members support to their organization. One is to create a sense of commitment within the organization; the other is to establish trust in the management. Both approaches appear to have a positive relationship with good internal communication.

\section{Research Hypotheses}

Although much research has examined the relationships between communication, trust and commitment, the directions and strength of these relationships have been somewhat mixed and therefore inconclusive. This is clearly demonstrated by the lack of agreement in the findings of previous research as well as by the fact the very few studies incorporated all three variables simultaneously. To address this gap, from the outset our research was to hypothesize and explore an initial two-way relationship between all three variables. Although our study is largely exploratory, we assume two-way relationships amongst all three variables as an initial step and propose to test the following hypotheses which are also depicted in an initial graphical model (see Figure 1)

Hypothesis 1: There is a statistically significant relationship between Communication and Trust 
Hypothesis 2: There is a statistically significant relationship between Trust and Commitment

Hypothesis 3: There is a statistically significant relationship between Communication and Commitment

\section{(Insert Figure 1 about here)}

\section{Data and Method}

The data examined here is based on an employee survey program involving a medium sized food processing organization operating in NSW (Australia). The organization has approximately 400 employees. The data reported here was collected in 2005 . This represents the latest survey data available due to a three year moratorium on the publication and analysis of results agreed by the researcher and the participating organization. The survey questionnaires were distributed to all of the organizations employees with their pay slip. They had the choice of returning the completed questionnaire by placing it in a box placed in the canteen area of the factory; or by sending it to the survey facilitator (i.e. the researchers). The survey did not ask respondents to provide any information that would identify them directly. 244 questionnaires were completed and returned giving an acceptable response rate of approximately $61 \%$.

\subsection{Participants}

A considerable majority of participant employees worked during the dayshift (65.2\%) and afternoon shift (27.9\%). The tenure of the participants show some stability in the organization with $34.6 \%$ of respondents reporting organizational membership for more than 10 years, 15.6\% between 6 and 10 years, 37.1\% between 1 and 5 years and $12.7 \%$ less than 1 year. Additionally $71.3 \%$ of respondents reported their employment status as full-time, with $4.5 \%$ reporting part-time employment status. $17.6 \%$ reported being employed by casual basis, with $6.6 \%$ selecting 'unknown employment status'.

Due to the requirements of managers and employee representatives information relating to age and gender was not requested. However it can be reported that the majority of employees working in the organization under examination were female. In addition $71.3 \%$ of respondents reported that they were working in a non-supervisory role, $21.7 \%$ in a supervisory role, with $7 \%$ reporting 'unknown'.

\subsection{Measures}

The ongoing survey was aimed at gauging employee views and ratings on a range of job-related and organization-wide issues. Amongst such issues are employee ratings of communication with supervisors \& managers trust in others - including colleagues, supervisors \& managers; and the level of loyalty (commitment) to the organization. Respondents were asked to indicate their levels of agreement with statements and ratings on the above characteristics. For simplicity (and not by researchers choice) the survey questionnaire used a four-point 'forced choice' scale: disagree strongly, disagree somewhat, agree somewhat and agree strongly. The adoption of a four-point rather than a five-point scale was decided as a result of long discussions and in conjunction with the wishes of key stakeholders including union leaders and organizational managers in the very early stages of the program. There was an overwhelming consensus that in this particular context, a five-point scale was to be avoided as it would most likely lead to a central tendency bias. In fact, that was actually demonstrated by pilot survey runs experienced in focus groups. While five-point Likert-type scales are generally preferred in social science attitudinal and behavioral surveys four point scale are still shown to offer acceptable reliability. By not including a neutral point in a scale, the respondent is compelled to make a decision. The argument is that the qualitative results between the conventional five/seven points scales and the scale used here are unaffected since if the respondents are truly neutral, then they will randomly choose one or the other, so forcing them to choose should not bias the overall results (Garland, 1991; Chang, 1994, Kahn et al, 2003). It is also suggested that the exclusion of a neutral point will draw the respondent to make a decision one way or the other. The more recent scientific studies have used this type of scale demonstrating that by eliminating a neutral level provides a better measure of the intensity of participants' attitudes or opinions' (see for example Perez et al, 2007)

\section{Analysis and Results}

The first stage of analysis was an examination of the measurement scales and their respective reliabilities. Examination of the Cronbach alpha reliability for the scale 'Communication' yielded favorable results with an alpha of 0.904. The four item scale of Commitment and Pride in working at FoodCo yields a Cronbach alpha the 0.752. The final scale examined was that of 'Trust'. This six item scale reports an acceptable Cronbach alpha 0.883. All of the three scales were shown to have acceptable scale reliability alpha coefficients. Details of the inter-item correlations for each of these constructs are shown in Appendix. 
The next step of our analysis was to examine the relationships between the three dimensions through correlation analysis. The results of that analysis are shown in Table 1. As we can see from the results presented in table 1 statistically significant positive correlations exist between all three variables. For the initial stage of exploratory data analysis, the researchers did not predict the direction of the relationship that may exist between the variables under examination. Consequently two-tailed Pearson correlations were conducted, examining the interrelationship for three variables, expressed in the correlation matrix of table 1.

\section{(Insert Table 1 about here)}

We can see from the results of table 1 that the strongest correlation identified was between the variables of communication and trust. This correlation coefficient of 0.645 represents what can be classified as a moderate to strong positive relationship. The next strongest relationship identified was between the variables of commitment and trust. Again this correlation was positive in nature, with coefficient of 0.478 representing a moderate relationship between the variables. Finally the correlation coefficient of 0.343 between communication and commitment represents a statistically significant, positive but weak correlation between these variables, by comparison.

\section{(Insert Figure 2 about here)}

While these results support our general hypotheses they do indicate that the fact that the above relationships vary in strength might suggest that the interrelations we had initially assumed are not strictly verified. In fact, based on the above correlations, we are tempted to conclude that Trust is definitely preceded by Effective Communication and that in turn it affects Commitment. The strength of the relationships we found is strongly indicative of this pattern, which also makes sense. If this is the case, then trust would play a moderating role in the relationships as depicted in Figure 3. Because of the nature of the data and the limited range of variables being examined, it is not methodologically possible to run alternative analyses (such as structural equations). However, we strongly believe that this pattern of relationships is worthy of consideration in future research where the nature of the data is more conducive to systematic testing, possibly through structural equation modeling.

\section{(Insert Figure 3 about here)}

\section{Conclusions and Discussions}

Previous research on the relationships between communication, trust and commitment has yielded mixed results. Although exploratory, the results of this study clearly indicate that while a close link exists between all of the three variables, the relationship between communication and trust is by far the strongest, followed by that between trust and commitment. These findings lend support to the strong logical assumption that trust is at the centre of this triadic relationship, while commitment is the end product of such relationship. In fact, much of the previous research has actually alluded to this, but in ways that were not always convincing (Robert and O'Reilly, 1974; Allert and Chatterjee, 1997; de Ridder, 2006; Tyler and Doerfel, 2006; Thomas et al, 2009). Our findings are in fact consistent with what has been argued, since the majority of studies seem to point to commitment as the desirable end of the equation. What has really escaped the minds of many researchers is that trust is still at the centre of the equation and that it is through trust that feelings of loyalty and commitment are formed. Yet, trust itself depends on a wide range of variables, of which, communication effectiveness is central. Trust is generated by true feelings of good communication amongst participants, including managers. It therefore requires authenticity, which also requires genuine and effective communication. In that regard, good two-way communications are often crucial and central. A frequent prescription in our daily life is "to be successful in life, you should learn to trust the people with whom you work." On reflection, this prescription is really alluding to the need to entertain good communication with people we work with. Good communication averts misperceptions which are often at the heart of feelings of mistrust. When feelings of trust are established, there would be a greater chance for true feelings of loyalty and commitment to take place. Although the results are modest and bear only on a limited sample size and are limited in geographical (including cultural) scope, they are truly indicative of the normative patterns of relationships between these three fundamental variables. The learning for managers is that trust does not just happen; it is forged and maintained through effective communication. Also, loyalty and commitment is most likely generated through nurturing true trusting relationships amongst the various actors, including employees \& managers.

\subsection{Implications for Management Practice and Future Research}

The results of this study bear strong relevance to management practice. They clearly indicate that to promote and build positive trust relationships senior managers must communicate well with their employees and do this as 
honestly and directly as possible, particularly during uncertain times (Whitener et al, 1998). This management style could boost morale and improve performance in a variety of ways. There's no such thing as employees being too informed. The sad thing today is that senior managers are so busy giving direction and orders that they fail to listen and subordinates decide to leave their brainpower at the door as they enter the workplace. People with suggestions are too often viewed as troublemakers or complainers. In this mode, no one can spell commitment to the organization and therefore would not trust its managers and leaders (de Ridder, 2006). When communication channels begin to deteriorate, misunderstandings and misrepresentations abound and a climate of mistrust sets in. People become suspicious; ignore each other, and play mind games in relationships. Lack of trust leads them to be afraid or angry at others they then disguise, distort, or ignore facts, feelings, or conclusions. When they don't trust their leader, they will refuse or resist his influence while insulating themselves from her/him. All this spells negativity and counterproductive behaviors for the leaders, the employees and for the organization as a whole, hence a poor "trust climate". However, the study has some limitations.

\subsection{Study Limitations and Suggestions for Future Research}

The empirical nature of this study lends it to several methodological limitations. The fact that this study focused on a single organization, it was not possible to make comparisons and therefore ascertain the relationships between communication, trust and commitment in different contexts. Because of the limited number of variables in the study, we could not test the sequencing of the variables in a more systematic way, through regression analysis. However, the above results provide further insight for future research which may consider putting the revised model on the "triadic" relationships between communication, trust and commitment to a more rigorous empirical testing by way of including a wider range of measures and by targeting a larger sample with a broader range of respondents in different contexts. Future research may consider such comparisons which may also spell differences in corporate cultures. Finally, the absence of measures of performance did not allow us to examine the implication of lack of communication, low trust climates (or mistrust in managers) on performance. This relationship is worthy of exploration in future research.

\section{References}

Allen, N., and Meyer, J. (1996). Affective, Continuance, and Normative Commitment to the Organization: An Examination of Construct Validity. Journal of Vocational Behavior, 49, 252-276.

Allert, J., and Chatterjee, S. (1997). Corporate communication and trust in leadership. Corporate Communications: An International Journal, 2 (1), pp. 14-21.

Anderson, J., and Narus, J. (1990). A model of distributor firm and manufacturer firm working relationships. Journal of Marketing, 54 (1), 42-58.

Ayoko, O., and Pekerti, A. (2008). The mediating and moderating effects of conflict and communication openness on workplace trust. International Journal of Conflict Management, 19(4), 297-318.

Ball, D., Coelho, P., and Machas, A. (2004). The role of communication and trust in explaining customer loyalty: an extension to the ECSI model. European Journal of Marketing, 38 (9/10), 1272-1293.

Bambacas, M., and Patrickson, M. (2008). Interpersonal communication skills that enhance organizational commitment. Journal of Communication Management, 12 (1), 51-72.

Chang, Lei. (1994). A Psychometric Evaluation of 4-Point and 6-Point Likert-Type Scales in Relation to Reliability and Validity. Applied Psychological Measurement, 18(3), 205-215.

Chory, R., and Hubbell, A. (2008). Organizational justice and managerial trust as predictors of antisocial employee responses. Communication Quarterly, 56 (4), 357-375.

de Ridder, Jan A. (2006). Organizational communication and supportive employees. Human Resource Management Journal, 14 (3), 20-30.

Dwyer, F., Schurr, P., and Oh, S. (1987). Developing Buyer-Seller Relationships. Journal of Marketing, 51 (2), $11-27$.

Ellonen, R., Blomqvist, K., and Puumalainen, K. (2008). The role of trust in organizational innovativeness. European Journal of Innovation Management, 11(2), 160-181.

Gaines, J. (1980). Upward communication in industry: an experiment. Human Relations, 33 (12), 929-942.

Garland Ron. (1991). The Mid-Point on a Rating Scale: Is it Desirable? Marketing Bulletin, 2 (3), 66-70.

Gopinath, C., and Becker, T. (2000). Communication, procedural justice, and employee attitudes: relationships under condition of divestiture. Journal of Management, 26 (1), 63-83. 
Guzley, R. (1998). Organizational Climate and Communication climate, Management Communciation Quarterly, 5(4), 379-402.

Harry S., \& Dennis, III. (2006). Communication climate: How's the 'weather' in your. BizTimes.com. Milwaukee and Southeastern Business Week, October 12, 2006.

Hess, J., and Story, J. (2005). Trust-based commitment: multidimensional consumer-based relationships. Journal of Consumer Marketing, 22 (6), 313-322.

Huang, X., Gattiker, T., and Schwarz, J. (2008). Interpersonal trust formation during the supplier selection process: the role of the communication channel. Journal of Supply Chain Management, 44(3), 53-75.

Iverson, Roderick D. Colin S. McLeod \& Peter J. Erwin. (1996). The role of employee commitment and trust in service relationships. Marketing Intelligence \& Planning, 14 (3), 36-44.

Jacobs, G. (2008). Constructing corporate commitment amongst remote employees: A disposition and predisposition approach. Corporate Communications: An International Journal, 13 (1), $42-55$.

Kahn, B; Nowlis, S \& Dhar, R. (2003). Indifference versus Ambivalence: The Effect of a Neutral Point on Consumer Attitude and Preference Measurement. [Online] Available: http://hops.wharton.upenn.edu/ideas/pdf/00-022.pdf (22.12.10)

Kottila, M., and Ronni, P. (2008). Collaboration and trust in two organic food chains. British Food Journal, 110 (4/5), 376-394.

Kwon, I., and Suh, T. (2005). Trust, commitment, and relationships in supply chain management: a path analysis. Supply Chain Management: an International Journal, 10(1), 26-33.

Kwon, I., and Suh, T. (2006). Factors affecting the level of trust and commitment in supply chain relationships. Journal of Supply Chain Management, 40 (2), 4-14.

Massey, G., and Kyriazis, E. (2007). Interpersonal trust between marketing and R\&D during new product development projects. European Journal of Marketing, 41 (9/10), 1146-1172.

Mellinger, G. (1956). Interpersonal trust as a factor in communication. The Journal of Abnormal and Social Psychology, 52 (3), 304-309.

Ozag, D. (2006). The relationship between the trust, hope, and normative and continuance commitment of merger survivors. Journal of Management Development, 25 (9), 870-883.

Perez, Concepcion, Rafael Galvez, Silvia Huelbes, Joaquin Insausti, Didier Bouhassira, Silvia Diaz, and Javier Rejas. (2007). Validity and reliability of the Spanish version of the DN4 (Douleur Neuropathique 4 questions) questionnaire for differential diagnosis of pain syndromes associated to a neuropathic or somatic component. Health and Quality Outcomes, 5(3), 66-78

Roberts, K., and O’Reilly, C. (1974). Measuring organizational communication. Journal of Appllied Psychology, 59 (3), 321-326.

Rosli, M., and Hussein, A. (2008). Communication Climate and Organizational Performances, Paper presentated to the Eighth International Conference on Knowledge, Culture \& Changes in Organizations, 5-8 August, 2008. Cambridge University (UK). [Online] Available: http://m08.cgpublisher.com/proposals/26/index_html\#author-0 (12.12.10).

Rotter, Julian B. (1967). A New Scale for the Measurement of Interpersonal Trust. Joumal of Personality, 35 (4), 651- 65.

Ruppel, C., and Harrington, S. (2000). The Relationship of Communication, Ethical Work Climate, and Trust to Commitment and Innovation. Journal of Business Ethics, 25(4), 313-328

Stevenson, W. B., \& Gilly, M. C. (1991). Information processing and problem solving: The migration of problems through formal positions and networks of ties. Academy of Management Journal, 34 (3), 918-928.

Tan, H., and Lim, A. (2009). Trust in Coworkers and Trust in Organizations. The Journal of Psychology, 143(1), 45-66.

Tang, Thomas Li-Ping \& Robert M. Fuller. (1995). Corporate Downsizing: What Managers Can Do to Lessen the Negative Effects of Layoffs. SAM Advanced Management Journal, Vol. 60(1), 234-245.

Thomas, G., Zolin, R., and Hartman, J. (2009). The central role of communication in developing trust and its effect on employee involvement. Journal of Business Communication, 46 (3), 287-310. 
Thornhill, A., Lewis, P., and Saunders, M. (1996). The role of employee communication in achieving commitment and quality in higher education. Quality Assurance in Education, 4 (1), 12-20.

Tyler, H., and Doerfel, M. (2006). Competitive and cooperative conflict communication climates: The influence of ombuds processes on trust and commitment to the organization. International Journal of Conflict Management, 17(2), 129 - 153

van den Hoff, B., and de Ridder, J. (2004). Knowledge sharing in context: the influence of organizational commitment, communication climate and CMC use on knowledge sharing. Journal of Knowledge Management, $8(6), 117-130$.

van Vuuren, M., de Jong, M., and Seydel, E. (2007). Direct and indirect effects of supervisor communication on organizational commitment. Corporate Communications: An International Journal, 12 (2), 116-128.

Varona, F. (1996). Relationship between communication satisfaction and organxiational commitment in three Guatemalan organizations. The Journal of Business Communication, 33 (2), 111-140.

Webster, J., and Wong, W. (2008). Comparing traditional and virtual group forms: identity, communication and trust in naturally occurring project teams. International Journal of Human Resource Management, 19(1), 41-62.

Welch, M., and Jackson, P. (2007). Rethinking internal communication: a stakeholder approach. Corporate Communications: An International Journal, 12 (2), 177-198

Willemyns, M., Gallois, C., and Callan, V. (2003). Trust me, I'm your boss: trust and power in supervisor-supervisee communication. International Journal of Human Resource Management, 14(1), 117-127.

Wong, A., and Sohal, A. (2002). An examination of the relationship between trust, commitment and relationship quality. International Journal of Retail \& Distribution Management, 30 (1), 34-50.

Table 1. Correlation matrix for the three variables of communication trust and commitment

\begin{tabular}{|c|c|c|c|c|}
\hline \multicolumn{5}{|c|}{ Correlations between Communication, Trust and Commitment } \\
\hline & & Commitment & Trust & Communication \\
\hline \multirow[t]{3}{*}{ Commitment } & Pearson Correlation & & & \\
\hline & Sig. (2-tailed) & & & \\
\hline & $\mathrm{N}$ & & & \\
\hline \multirow[t]{3}{*}{ Trust } & Pearson Correlation & $.478^{* *}$ & & \\
\hline & Sig. (2-tailed) & .000 & & \\
\hline & $\mathrm{N}$ & 386 & & \\
\hline \multirow[t]{3}{*}{ Communication } & Pearson Correlation & $.343^{* *}$ & $.645^{* *}$ & \\
\hline & Sig. (2-tailed) & .000 & .000 & \\
\hline & $\mathrm{N}$ & 386 & 385 & \\
\hline$* *$. & Correlation is signific & nt at the 0.01 le & el (2-ta & led). \\
\hline
\end{tabular}


Table 2. Inter-item correlations for scale of 'Communication'

\begin{tabular}{lcccccc}
\hline & Item & Item & Item & Item & Item & Item \\
& 1 & 2 & 3 & 4 & 5 & 6 \\
\hline Item 1. Area managers and supervisors communicate well & 1.000 & & & & & \\
with us & & & & & & \\
Item 2. Rating of Communication between you and your & .598 & 1.000 & & & & \\
Supervisor & & & & & & \\
Item 3. Rating of Communication with Area Managers & .580 & .660 & 1.000 & & & \\
Item 4. Rating of Communication with Area Supervisors & .620 & .746 & .848 & 1.000 & & \\
Item 5. Rating of Communication between my Area and the & .447 & .588 & .702 & .685 & 1.000 \\
other Areas/Departments & & & & & & \\
Item 6. Rating of Communication with Senior Management & .378 & .510 & .604 & .564 & .638 & 1.000 \\
\hline
\end{tabular}

Table 3. Inter-item correlations for scale of 'Commitment'

\begin{tabular}{lrrrr}
\hline & Item & Item & Item & Item \\
& 1 & 2 & 3 & 4 \\
\hline Item 1. I am proud to tell others that I am part of this organization & 1.000 & & & \\
Item 2. I really care about the fate of this organization & .288 & 1.000 & & \\
Item 3. This organization really inspires the very best in me in the way of job & .463 & .310 & 1.000 & \\
performance & & & & \\
Item 4. I am extremely glad that I chose $\quad$ this organization to work for & .502 & .414 & .612 & 1.000 \\
\hline
\end{tabular}

Table 4. Inter-item correlations for scale of 'Trust'

\begin{tabular}{|c|c|c|c|c|c|c|}
\hline & $\begin{array}{c}\text { Item } \\
1\end{array}$ & $\begin{array}{c}\text { Item } \\
2\end{array}$ & $\begin{array}{c}\text { Item } \\
3\end{array}$ & $\begin{array}{c}\text { Item } \\
4\end{array}$ & $\begin{array}{c}\text { Item } \\
5\end{array}$ & $\begin{array}{c}\text { Item } \\
6\end{array}$ \\
\hline $\begin{array}{l}\text { Item } 1 . \text { I believe that most people in this workplace have } \\
\text { good intention }\end{array}$ & 1.000 & & & & & \\
\hline $\begin{array}{l}\text { Item 2. I have faith/trust in the promises or statements of } \\
\text { Colleagues (co-workers) here }\end{array}$ & .560 & 1.000 & & & & \\
\hline $\begin{array}{l}\text { Item 3. I have faith/trust in the promises or statements of } \\
\text { Line Supervisors here }\end{array}$ & .390 & .539 & 1.000 & & & \\
\hline $\begin{array}{l}\text { Item 4.I have faith/trust in the promises or statements of } \\
\text { Area Supervisors here }\end{array}$ & .411 & .473 & .786 & 1.000 & & \\
\hline $\begin{array}{l}\text { Item } 5 . \text { I have faith/trust in the promises or statements of } \\
\text { Area managers here }\end{array}$ & .416 & .412 & .686 & .812 & 1.000 & \\
\hline $\begin{array}{l}\text { Item } 6 . \text { I have faith/trust in the promises or statements of } \\
\text { Senior managers here }\end{array}$ & .384 & .403 & .620 & .681 & .770 & 1.000 \\
\hline
\end{tabular}




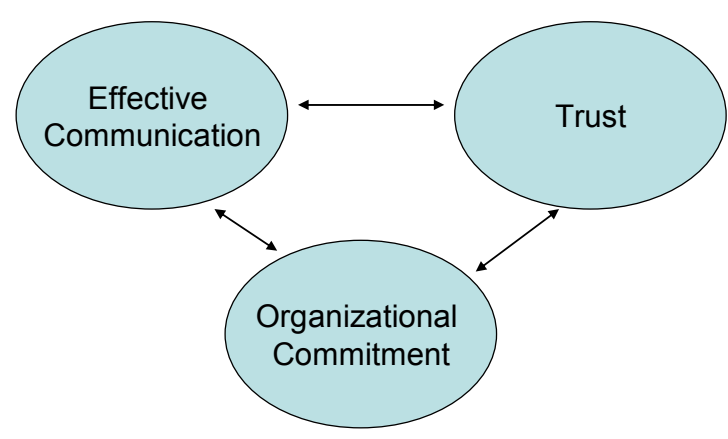

Figure 1. Initial Hypothetical Exploratory Model

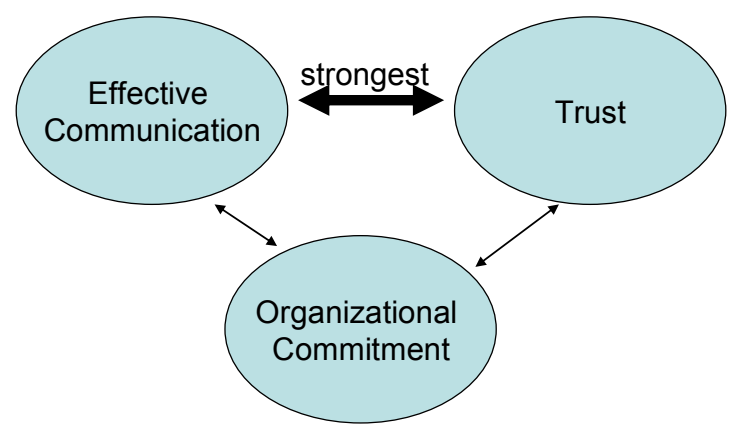

Figure 2. Findings

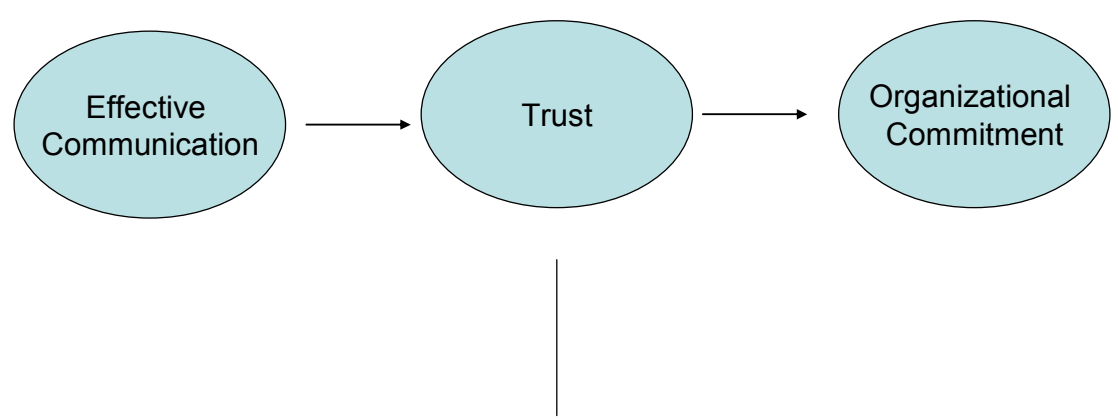

Trust precedes commitment And/or moderates the impact of communication on commitment

Figure 3. An Alternative-Consideration for future research 